Article

\title{
Hierarchical NiO/CMK-3 Photocathode for a $p$-Type Dye-Sensitized Solar Cell with Improved Photoelectrochemical Performance and Fast Hole Transfer
}

\author{
Jie Qu ${ }^{1}$, Zhaoyang Fan ${ }^{2, *}$, Hamed Mira ${ }^{3}$, Jianan Wang ${ }^{2,4, *}$, Amor M. Abdelkader ${ }^{5, *} \mathbb{C}$ \\ and Shujiang Ding ${ }^{2}$ \\ 1 College of Chemistry and Chemical Engineering, Hunan Normal University, Changsha 410081, China; \\ qujie@hunnu.edu.cn \\ 2 Xi' an Key Laboratory of Sustainable Energy Materials Chemistry, MOE Key Laboratory for Nonequilibrium \\ Synthesis and Modulation of Condensed Matter, State Key Laboratory of Electrical Insulation and Power \\ Equipment, Department of Applied Chemistry, School of Science, Xi'an Jiaotong University, Xi'an 710049, \\ China; dingsj@xjtu.edu.cn \\ 3 Nuclear Materials Authority, Cairo 11381, Egypt; hamedmira@yahoo.com \\ 4 Department of Environmental Science and Engineering, State Key Laboratory of Multiphase Flow in Power \\ Engineering, Xi'an Jiaotong University, Xi'an 710049, China \\ 5 Faculty of Science and Technology, Bournemouth University, Poole, Dorset BH12 5BB, UK \\ * Correspondence: z.y.fan@stu.xjtu.edu.cn (Z.F.); wangjn116@xjtu.edu.cn (J.W.); \\ aabdelkader@bournemouth.ac.uk (A.M.A.)
}

Academic Editors: Fatwa Firdaus Abdi and Derek J. McPhee

Received: 18 February 2020; Accepted: 27 March 2020; Published: 2 April 2020

\begin{abstract}
The sluggish photoelectrochemical performance of $p$-type dye-sensitized solar cells ( $p$-DSSCs) has hindered its commercial use. In this work, we introduce a novel hierarchical nanocomposite of $\mathrm{NiO}$ nanoparticles anchored on highly ordered mesoporous carbons CMK-3 (NiO/CMK-3). Using CMK-3 as a backbone effectively prevented the self-aggregation of $\mathrm{NiO}$ nanoparticles and subsequently increased the total specific surface area of the composite for more dye adsorption. The interconnected conductive networks of CMK-3 also served as a split-flow high-speed channel, which was beneficial for hole spin-flow to accelerate hole transfer. The hierarchical $\mathrm{NiO} / \mathrm{CMK}-3$ photocathode improved the photovoltaic conversion efficiency to $1.48 \%$ in a cell with a Cobalt(II)/(III) electrolyte and a PMI-6T-TPA dye.
\end{abstract}

Keywords: NiO; CMK-3; Fast hole transport; Solar cell

\section{Introduction}

Conventional low-cost dye-sensitized solar cells based on $n$-type nanocrystalline $\mathrm{TiO}_{2}$ photoanodes (n-DSSCs) have attracted great interest for several years. The photocurrent is generated in these devices from dye-sensitized electron injection into $n$-type semiconductors, and conversion efficiency values as high as $12.3 \%$ have been reported [1]. Recently, dye-sensitized solar cells based on $p$-type semiconductors ( $p$-DSSCs) have also attracted growing attention [2-5]. These have comparable theoretical efficiency to the $n$-DSSCs and similar operating principles with only the nature of the photoinjected charges being different. In addition, $p$-DSSCs can be combined with $n$-DSSCs to assemble a tandem solar cell ( $p n$-DSSCs), with both electrodes becoming photoactivated. A theoretical upper limit efficiency of $43 \%$ can be achieved for such devices, which is much higher than that of single-junction solar cells [2,6]. However, the photoelectrical performance of $p$-DSSC is limited by intrinsically low voltages and currents. Such low photocurrents represent a major performance limitation in $p$-DSSCs. 
They are caused by (i) the fast charge recombination between the redox mediator dye and holes generated in the $\mathrm{NiO}$ and (ii) the overall low light-harvesting efficiency $[7,8]$. It is believed that the nature and morphology of nanocrystalline $\mathrm{NiO}$ has a great influence on the hole transfer processes that occur in the semiconductor electrode [9-14]. Although $\mathrm{NiO}$ nanoparticles were viewed as a promising material for $p$-DSSCs, they cannot fulfill all of the requirements for the target application. Two major limitations are the low intrinsic electric conductivity and hole diffusion coefficient of $\mathrm{NiO}$ films, which can hinder rapid charge flow and favor charge recombination between the excited state of the electrolyte and the excited electron within the dye molecule [15-18]. Besides, nanocrystalline NiO films have a relatively low Brunner-Emmett-Teller (BET) surface area and transparency, which restrains light harvesting and the penetration depth of light. Therefore, it is necessary to develop novel $\mathrm{NiO}$ nanostructures that can suppress the recombination and enhance the light absorption. Combining $\mathrm{NiO}$ nanoparticles with conductive nanomaterials, such as graphene, was a promising strategy to obtain high conductivity and larger surface area [19]. NiO hybrids with graphene, for example, yielded a significant improvement in the charge transfer, resulting in a reasonably high short-circuit photocurrent of $0.27 \mathrm{~mA}$ $\mathrm{cm}^{-2}$ and an open-circuit photovoltage of $105 \mathrm{mV}$ [19]. However, the power conversion efficiency in this device is still very low. Highly crystalline nanostructured nickel (II) oxide microballs were developed with a high specific surface area and favorable optical properties. After sensitization with PMI-6T-TPA (perylenemonoimid-six thiophene-triphenylamine, the structure is shown in Figure S1), a record JSC of $7.0 \mathrm{~mA} \mathrm{~cm}^{-2}$ and overall conversion efficiency of $0.43 \%$ were obtained [20]. There have been considerable efforts to improve the photoelectrochemical performance of $p$-DSSCs. Nevertheless, it is still not on a comparable level to that of $n$-DSSCs, which is due to the mismatching of dye, electrolyte, and $p$-type semiconductor.

In this article, a novel hierarchical NiO/CMK-3 nanocomposite was prepared using CMK-3 as a template. CMK-3 was utilized as a backbone to support $\mathrm{NiO}$ nanoparticles and was able to prevent self-aggregation and increase surface area effectively. The thin NiO layers with a large BET surface were found to be more favorable for dye adsorption, and the spaces constructed by $\mathrm{NiO}$ layers were able to accommodate more light. In addition, the inherent array channels of CMK-3 can be conducive for fast hole transport, and its interconnected conducting networks can be beneficial for hole spin-flow to accelerate hole transfer, serving as split-flow high-speed channels. A cobalt(II)/(III) electrolyte was used in our devices. This has a redox potential that is approximately $340 \mathrm{mV}$ more negative than that of typical $\mathrm{I}^{-} / \mathrm{I}_{3}^{-}$electrolytes and should theoretically allow for increased open-circuit voltage. PMI-6T-TPA was used to sensitize the mesoporous $\mathrm{NiO}$ photocathode. An energy-level diagram for the as-prepared $p$-DSSC is shown in Figure 1. Together with this novel hierarchical NiO/CMK-3 nanocomposite, a photovoltaic conversion efficiency of $1.48 \%$ was achieved.

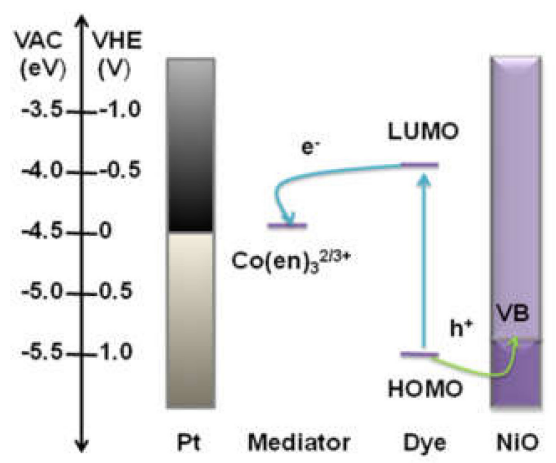

Figure 1. Energy level diagram for the prepared $p$-type dye-sensitized solar cell ( $p$-DSSC).

\section{Results}

X-ray diffraction (XRD) patterns of the $\mathrm{NiO}$ and $\mathrm{NiO} / \mathrm{CMK}-3$ composite samples are shown in Figure 2a. All the diffraction peaks match well with cubic rock salt NiO (JCPDS File No. 78-0643). The sharp peaks indicate high levels of crystallinity of $\mathrm{NiO}$. A characteristic diffraction peak of graphitic 
carbon appears at around $25^{\circ}$, which can be attributed to CMK-3 [21]. The broad peak indicates that CMK-3 does include a stacked crystalline graphitic phase as a component. The conductivity of CMK-3 with such a graphitic phase can be improved, and CMK-3 can serve as a shuttle to enhance electron transport and suppress recombination [19]. The thermal gravimetric analysis (TGA) curve (Figure 2b) shows the thermal stability of the NiO/CMK-3 composite. The slight weight loss at temperatures under $100{ }^{\circ} \mathrm{C}$ can be attributed to the evaporation of residual water from the preparation process. A more substantial weight loss step occurs between $350-510{ }^{\circ} \mathrm{C}$ and can be attributed to the combustion of crystallized CMK-3 [22]. The content of $\mathrm{NiO}$ in this composite is estimated from the TGA curve to be $51.2 \mathrm{wt} \%$.
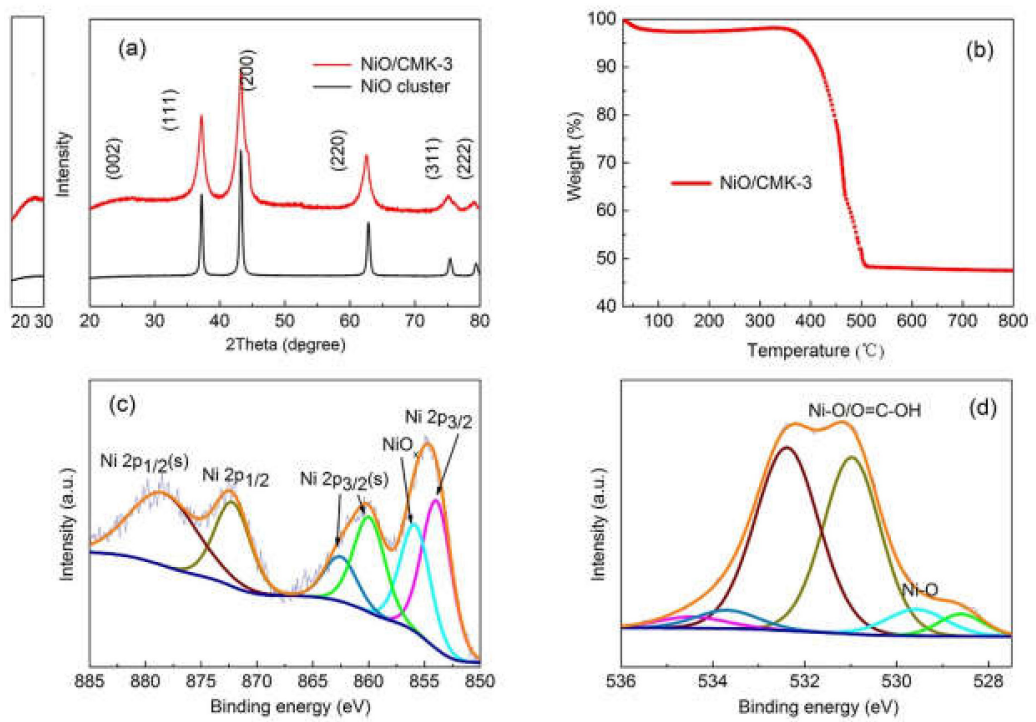

Figure 2. (a) $\mathrm{XRD}$ of the $\mathrm{NiO} / \mathrm{CMK}-3$ composite and $\mathrm{NiO}$ cluster; (b) Thermal gravimetric analysis (TGA) curve of NiO/CMK-3 composite; (c) Ni 2p XPS spectrum of NiO/CMK-3 composite, wine line: $\mathrm{Ni}^{2+}\left(\mathrm{Ni} 2 \mathrm{p}_{1 / 2} \mathrm{~s}\right)$, dark yellow line: $\mathrm{Ni}^{2+}\left(\mathrm{Ni}_{2} \mathrm{p}_{1 / 2}\right)$, dark cyan line: $\mathrm{Ni}^{2+}\left(\mathrm{Ni}_{2} \mathrm{p}_{3 / 2} \mathrm{~s}\right)$, green line: $\mathrm{Ni}^{2+}$ $\left(\mathrm{Ni} 2 \mathrm{p}_{3 / 2} \mathrm{~s}\right)$, cyan line: $\mathrm{Ni}^{3+}$, magenta line: $\mathrm{Ni}^{2+}\left(\mathrm{Ni}_{2} \mathrm{p}_{3 / 2}\right)$; (d) O1s XPS spectrum of NiO/CMK-3 composite, wine line: $\mathrm{O}^{2+}\left(\mathrm{NiO}_{\mathrm{x}}\right)$, dark yellow line: $\mathrm{O}^{2+}(\mathrm{NiO}, \mathrm{C}=\mathrm{O})$, dark cyan line: $\mathrm{O}^{2+}\left(\mathrm{H}_{2} \mathrm{O}\right)$, green line: $\mathrm{O}^{2+}(\mathrm{NiO})$, cyan line: $\mathrm{O}^{2+}(\mathrm{NiO})$.

X-ray photoelectron spectroscopy (XPS) was used to analyze the chemical compositions and the possible bonds between the constituents of the prepared NiO/CMK-3 nanocomposite. All elements (Ni, O, and C) relevant to NiO/CMK-3 nanocomposite were observed (Figure S3a). Figure 2c,d show the high-resolution spectra of Ni2p and O1s. There are two regions for Ni2p spectra; one is the $\mathrm{Ni} 2 \mathrm{p}_{3 / 2}$ of $851-866 \mathrm{eV}$, the other is $\mathrm{Ni} 2 \mathrm{p}_{1 / 2}$ spin-orbit levels of $870-885 \mathrm{eV}$. The main peak in the Ni2 $\mathrm{p}_{3 / 2}$ region at $854 \mathrm{eV}$ is indexed to the $\mathrm{Ni}^{2+}$ in the $\mathrm{Ni}-\mathrm{O}$ bonding configuration [23-26]. While the shoulder peak at $856 \mathrm{eV}$ stems from the $\mathrm{Ni}^{2+}$-vacancy induced $\mathrm{Ni}^{3+}$ ion or excess oxygen from compounds such as oxyhydroxides $(\mathrm{NiIIIOOH})[27,28]$. To further investigate the species, as described in the experimental section, the nanocomposite samples were calcined at $600^{\circ} \mathrm{C}$. Under this thermal treatment, $\mathrm{NiOOH}$ species can be obviously reduced. So $\mathrm{Ni}^{3+}$ is mainly induced by $\mathrm{Ni}^{2+}$-vacancy, which can generate $p$-type conductivity in the $\mathrm{NiO}_{x}$ [29]. As shown in Figure 2d, the peaks at 528.6 and $529.6 \mathrm{eV}$ are due to lattice oxygen of $\mathrm{NiO}$. The $\mathrm{O} 1$ s peak at $531 \mathrm{eV}$ is attributed to $\mathrm{O}^{2-}$ of $\mathrm{NiO}$ and $\mathrm{C}=\mathrm{O}$, while the peak at $532.5 \mathrm{eV}$ is usually associated with defects of $\mathrm{NiO}[26,30,31]$. Figure S3b displays the $\mathrm{C} 1 \mathrm{~s}$ spectra. The peaks at 283.8 and $284.2 \mathrm{eV}$ correspond to $\mathrm{C}-\mathrm{C}$ or $\mathrm{C}=\mathrm{C}$. While the other three peaks at 285.4, 286.9, and 287.9 are attributed to $\mathrm{C}=\mathrm{O} / \mathrm{C}-\mathrm{O}, \mathrm{COO}$, and $\mathrm{C}=\mathrm{O}$, respectively [32].

The structure of the CMK-3 and the schematic illustration of the synthetic process of the Ni-precursor/CMK-3 are shown in Figure S2. The morphology of the as-prepared NiO/CMK-3 nanocomposite was determined from scanning electron microscopy (SEM) and transmission electron 
microscopy (TEM) images (Figure 3). Figure 3a indicates a uniform distribution of NiO on CMK-3. The TEM images indicate that the NiO layer is wrapped around a CMK-3 backbone. The NiO layer is composed of nanoparticles with diameters in the range of 3-5 nm (Figure 3d). The NiO aggregates together to form a solid cluster that combine to form a continuous layer (Figure 3f). The interplanar distance measured from a high-resolution transmission electron microscopy (HRTEM) image is $0.21 \mathrm{~nm}$, corresponding to the (200) plane of cubic NiO [33]. The selected-area electron diffraction (SAED) pattern is shown in Figure 3e. Five diffraction rings are presented in the picture, which can be attributed to the (111), (200), (220), (311), and (222) planes of the NiO lattice, respectively. In addition, the morphology of the $\mathrm{NiO}$ cluster was also tested. The elemental mapping (Figure 4) further confirmed the uniform distribution of the $\mathrm{NiO}$ nanoparticles in the composite. $\mathrm{C}$ is located at the center of the $\mathrm{NiO} / \mathrm{CMK}-3$ composite, forming the core, while $\mathrm{Ni}$ and $\mathrm{O}$ elements hold a wider area, which verifies that $\mathrm{NiO}$ covers the surface of CMK-3.
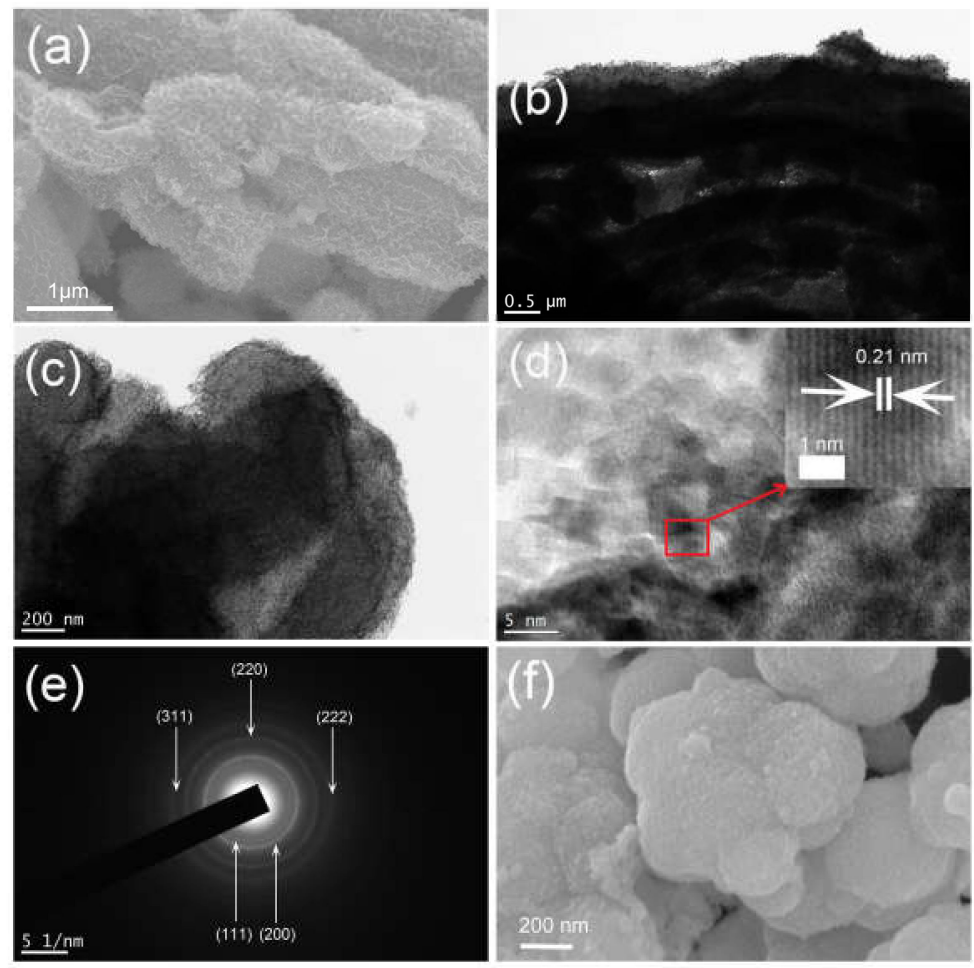

Figure 3. SEM (a), TEM (b,c), HRTEM (d), and SAED images (e) of NiO/CMK-3 composite; SEM image (f) of $\mathrm{NiO}$ cluster. 


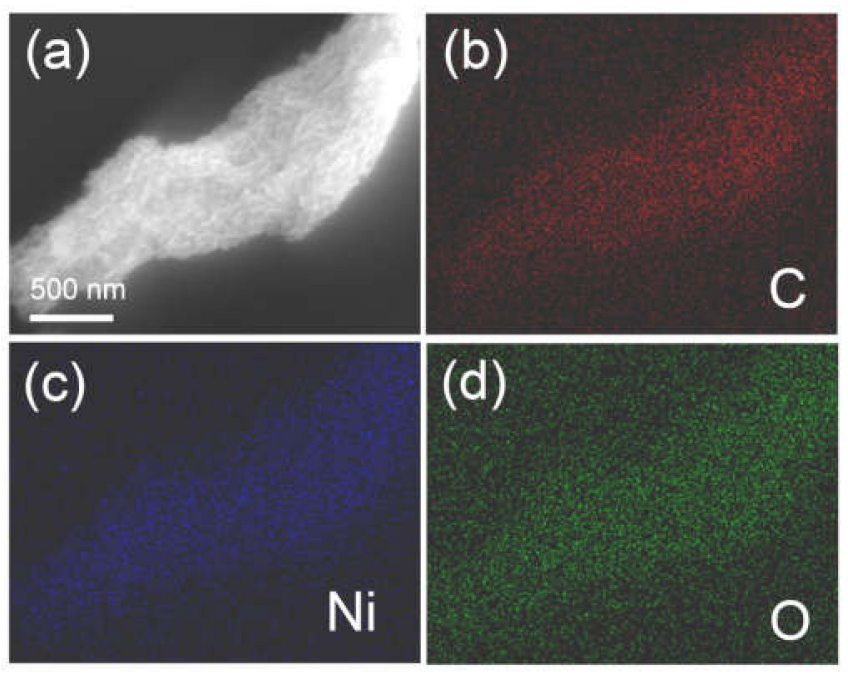

Figure 4. SEM image (a) of $\mathrm{NiO} / \mathrm{CMK}-3$ composite and the corresponding elemental mapping images of carbon (b), nickel (c), and oxygen (d).

\section{Discussion}

To investigate the photoelectrochemical performance of the NiO/CMK-3 composite, we assembled a $p$-DSSC device in which NiO was used to fabricate the photocathode. The $p$-DSSC structure and the electron-transfer processes are shown in Figure 5a. It should be noted that double-layered $\mathrm{NiO}$ was used in this device. A compact NiO blocking layer was first deposited on fluorine-doped tin oxide (FTO) glass, and then a hierarchical NiO/CMK-3 or NiO-clusters layer was applied. A compact $\mathrm{NiO}$ blocking layer can effectively improve the overall photoelectrical performance (for example, short circuit current density: $J_{s c}$, open circuit voltage: $V_{o c}$, fill factor: FF and photovoltaic conversion efficiency: $\eta$ ), and suppress hole transfer recombination, so as to increase hole collection efficiency $[2,11,34]$.
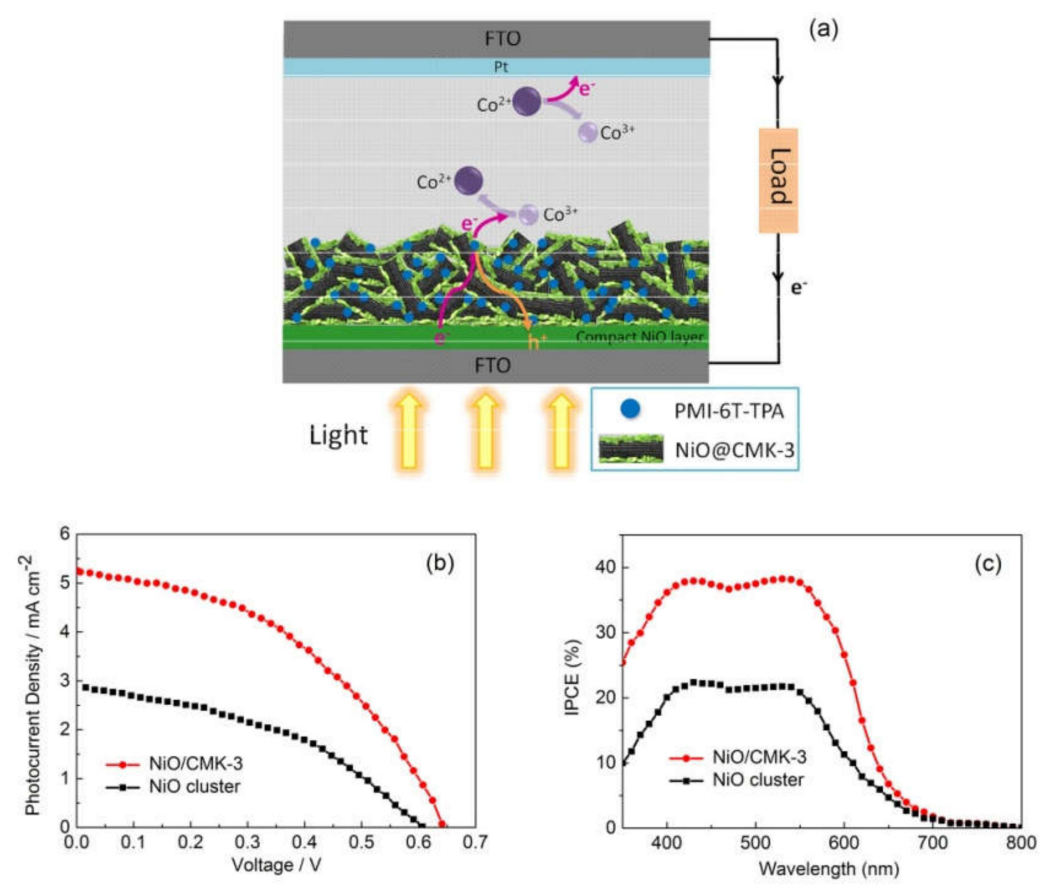

Figure 5. (a) $p$-DSSC structure and scheme for the electron-transfer processes occurring in the $p$-DSSC; (b) Current-density-voltage characteristics of $p$-DSSCs; (c) IPCE spectra of $p$-DSSCs sensitized by PMI-6T-TPA. 
Figure $5 \mathrm{~b}$ shows the photocurrent-voltage curves of $p$-DSSCs based on-hierarchical NiO/CMK-3 tested under simulated sun illumination (AM 1.5). The photocurrent-voltage curve of a controlled device fabricated using $\mathrm{NiO}$-cluster photocathodes is also illustrated in Figure $5 \mathrm{~b}$ for comparison. The device based on hierarchical NiO/CMK-3 shows a higher $\mathrm{J}_{\mathrm{sc}}\left(5.25 \mathrm{~mA} \mathrm{~cm}{ }^{-2}\right)$ than that based on $\mathrm{NiO}$ clusters $\left(2.86 \mathrm{~mA} \mathrm{~cm}^{-2}\right)$. The higher $\mathrm{J}_{\mathrm{sc}}$ of the $\mathrm{NiO} / \mathrm{CMK}-3$ can be explained by the high specific surface area of the nanocomposite $\left(508 \mathrm{~m}^{2} \mathrm{~g}^{-1}\right)$, which is far higher than that previously reported [9,19,20,35-37]. CMK-3 has a high specific surface of $1091 \mathrm{~m}^{2} \mathrm{~g}^{-1}$, and in the hierarchical structure acts as a template that effectively prevents the self-aggregation of $\mathrm{NiO}$. $\mathrm{NiO}$ clusters, on the other hand, are easily agglomerated, with a total specific surface area of only $45 \mathrm{~m}^{2} \mathrm{~g}^{-1}$. With a higher available surface area, far more PMI-6T-TPA molecules can attach onto the hierarchical NiO/CMK-3 and improve the short circuit current density of the solar cell. The $\mathrm{V}_{\mathrm{Oc}}$ values are determined by the difference of the quasi-Fermi level of $\mathrm{NiO}$ and redox potential of the electrolyte. In the current work $\left[\mathrm{Co}(\mathrm{en})_{3}\right]^{2+/ 3+}$ is used as a redox mediator, which shows a much higher vacuum energy value with respect to $\mathrm{NiO}$ and should result in higher $\mathrm{V}_{\mathrm{oc}}$ [38]. The $\mathrm{V}_{\mathrm{oc}}$ values of both samples here are above $600 \mathrm{mV}$, with the value of the hierarchical NiO/CMK-3 device being $34 \mathrm{mV}$ higher than for that based on $\mathrm{NiO}$ clusters. As reported previously, hole transport processes can also influence the $\mathrm{V}_{\mathrm{oc}}$ in $p$-DSSCs. When hierarchical NiO/CMK-3 was used as a photocathode, injected holes are transferred rapidly from $\mathrm{NiO}$ to $\mathrm{CMK}-3$, acting as a split-flow high-speed channel for faster hole transport through the external circuit. This allows for favorable energy level alignment and strong interactions between the $\mathrm{NiO}$ and the CMK-3 backbone. During this process, hole recombination is suppressed and results in an increased value of $\mathrm{V}_{\mathrm{OC}}$ and enhances the overall device performance. The details of $\mathrm{J}_{\mathrm{sc}}, \mathrm{V}_{\mathrm{oc}}$, FF, and $\eta$ are listed in Table 1 . Consequently, a higher photovoltaic conversion efficiency of $1.48 \%$ is obtained for the device based on the hierarchical NiO/CMK-3 nanocomposite, which is double that of the device based on $\mathrm{NiO}$ clusters $(0.71 \%)$.

Table 1. Detailed photovoltaic parameters of the as-prepared $p$-DSSCs.

\begin{tabular}{ccccc}
\hline Sample & $J_{\text {sc }}\left(\mathbf{m A ~ c m}^{-2}\right)$ & $V_{\text {oc }}(\mathbf{m V})$ & $\boldsymbol{F F}$ & $\left.\eta(\mathbf{c} /)^{\prime}\right)$ \\
\hline $\mathrm{NiO} / \mathrm{CMK}-3$ & 5.25 & 641 & 0.44 & 1.48 \\
\hline $\mathrm{NiO}$ cluster & 2.86 & 607 & 0.41 & 0.71 \\
\hline
\end{tabular}

$p$-DSSC based on $\mathrm{NiO} / \mathrm{CMK}-3$ shows a two-fold increase in $\mathrm{J}_{\mathrm{sc}}$ than that based on $\mathrm{NiO}$ cluster. Such trends were also reflected in the incident photon-to-charge carrier conversion efficiency (IPCE) spectra, as shown in Figure 5c. A broad plateau between 400 and $570 \mathrm{~nm}$ was observed for both samples and trailed off up to $700 \mathrm{~nm}$ [20]. IPCE values for NiO/CMK-3 based $p$-DSSCs are generally higher than those of $\mathrm{NiO}$ cluster-based $p$-DSSCs. A further increase in dye loading may result in the improvement of the IPCE value. The highest value close to $40 \%$ occurred for $\mathrm{NiO} / \mathrm{CMK}-3 \mathrm{based}$ $p$-DSSCs. Finally, the real tested $\mathrm{J}_{\mathrm{sc}}$ values are very close to the theoretically calculated $\mathrm{J}_{\mathrm{sc}}$ values.

Electrochemical impedance spectroscopy (EIS) was carried out under the same conditions as the photocurrent-voltage (I-V) testing to further understand the charge transfer processes in the NiO/CMK-3 nanocomposite. The Nyquist plots (Figure 6) show two distinct semicircles; one in the low-frequency range and one in the high-frequency range. The low-frequency semicircle on the right of the plot corresponds to hole transport in the mesoscopic NiO film $\left(R_{t}\right)$ and the back reaction occurring at the $\mathrm{NiO} /$ dye/electrolyte interface $\left(\mathrm{R}_{\mathrm{rec}}\right)$. The second semicircle in the high-frequency range, on the left of the plot, can be assigned to the electrolyte/Pt electrode interface $\left(R_{p t}\right)[2,14]$. The above detailed fitting parameters are achieved by a transmission line equivalent circuit as summarized in Table 2 , Figure S5 and Table S1 [2,14,39]. $\mathrm{R}_{\mathrm{pt}}$ values of the two $p$-DSSCs are relatively similar, which might be due to the comparable device structure. The $\mathrm{R}_{\mathrm{t}}$ values obtained, however, are distinctly different, the value determined for the NiO/CMK-3 device is significantly lower than that for the NiO-cluster device. This indicates much faster hole transport in the NiO/CMK-3 film, which may occur due to the split-flow high-speed route of the CMK-3 backbone. The $R_{\text {rec }}$ value of NiO/CMK-3 is much higher 
than that of the $\mathrm{NiO}$ cluster, implying prohibited recombination at the $\mathrm{NiO} / \mathrm{CMK}-3 /$ dye/electrolyte interface. The hole lifetime $\left(\tau_{h}\right)$ can be determined using the Equation $\tau_{h}=1 / 2 \pi f_{\min }$ from the IMVS results, while hole transport time $\left(\tau_{\text {th }}\right)$ can be determined using the Equation $\tau_{\text {th }}=1 / 2 \pi f_{\min }$ from the IMPS results $\left(f_{\min }\right.$ corresponds to the frequency at the bottom of the spectrum plot) $[40,41]$. The IMPS and IMVS results are shown in Figure S4, and the calculated $\tau_{\mathrm{h}}$ and $\tau_{\text {th }}$ values are shown in Table 2. The charge collection efficiency $\left(\eta_{c c}\right)$ can be calculated from the hole transport time $\left(\tau_{\text {th }}\right)$ and lifetime $\left(\tau_{h}\right)$ using the Equation: $\eta_{c c}=1-\tau_{t h} / \tau_{h}$ [14]. The calculated parameters are summarized in Table 2. The hole lifetime of NiO/CMK-3 is longer than that of the NiO cluster, indicating a lower rate of recombination, which is beneficial for $p$-DSSCs. The shorter hole transport time for $\mathrm{NiO} / \mathrm{CMK}-3$ than that of the $\mathrm{NiO}$ cluster can be attributed to the high electrical conductivity and the well-designed structure of CMK-3. The $\tau_{\mathrm{h}} / \tau_{\text {th }}$ ratio for NiO/CMK-3 is 7.1, more than double that for the $\mathrm{NiO}$-cluster device and is an indication of reduced recombination. As schematically demonstrated in Figure 7, the inside channels of CMK-3 provide a direct hole transport route, just like the high speed route, which can shorten the hole transport time. Moreover, the interconnected nanorods of CMK-3 are more beneficial for fast hole transfer. The holes will travel into other nanorods when there are many more holes. Fast hole transport can also reduce the recombination with the electrolytes. In short, the favorable morphological characteristics lead to enhancement of the photoelectrochemical performance. The hierarchical NiO/CMK-3 sample exhibits an enhanced charge collection efficiency of $85 \%$, which can be attributed to reduced recombination and faster hole transport. The hole diffusion length $\left(L_{n}\right)$, a characteristic length scale, is defined by Equation $\left(L_{n}=d \sqrt{\tau_{h} / \tau_{t h}}\right)$. It is obvious that $\mathrm{NiO} / \mathrm{CMK}-3$ shows longer $L_{n}$ compared to the $\mathrm{NiO}$ cluster. It is well-known that for an efficient hole transport $L_{n}$ should be larger than the film thickness; the $L_{n}$ value of $\mathrm{NiO} / \mathrm{CMK}-3$ is more than two times larger than the $2 \mu \mathrm{m}$ thickness of the $\mathrm{NiO}$ film. The above results are in good agreement with those previously reported [34], which also indicates that hole transport and recombination kinetics are to some extent related to the intrinsic properties of the photocathode semiconductors.

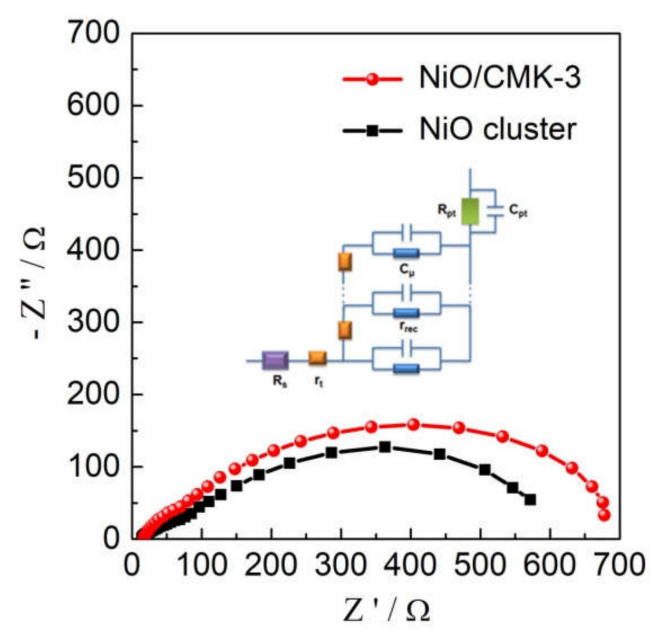

Figure 6. Nyquist plots of the $p$-DSSCs made of two nanomaterials and the insert is the equivalent circuit for the impedance spectrum. $R_{s}$ : serial resistance; $R_{t}$ : transport resistance of the film; $R_{\text {rec }}$ : the recombination resistance of the film; $R_{p t}$ : charge-transfer resistance of Pt electrode; $C_{\mu}$ : distributed capacitance of $p$-semiconductor; $\mathrm{C}_{\mathrm{pt}}$ : the double-layer capacitance of the platinized counter electrode.

Table 2. Fitted and calculated data from EIS, IMPS, and IMVS spectra of $p$-DSSC s based on NiO/CMK-3 and $\mathrm{NiO}$-cluster photocathodes.

\begin{tabular}{cccccccc}
\hline Sample & $\mathbf{R}_{\mathbf{p t}}(\boldsymbol{\Omega})$ & $\mathbf{R}_{\mathbf{t}}(\boldsymbol{\Omega})$ & $\mathbf{R}_{\text {rec }}(\boldsymbol{\Omega})$ & $\tau_{\boldsymbol{t h}}(\mathbf{m s})$ & $\tau_{\boldsymbol{h}}(\mathbf{m s})$ & $\eta_{c c}$ & $L_{\boldsymbol{n}}(\boldsymbol{\mu m})$ \\
\hline $\mathrm{NiO} / \mathrm{CMK}-3$ & 37 & 89 & 614 & 11 & 78 & 0.86 & 5.33 \\
\hline $\mathrm{NiO}$ cluster & 41 & 197 & 508 & 20 & 52 & 0.62 & 3.22 \\
\hline
\end{tabular}




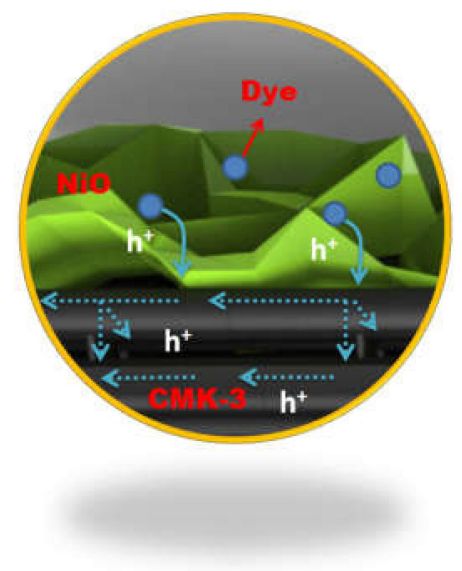

Figure 7. The schematic representation of the hole transfer path in the NiO/CMK-3 structure.

\section{Materials and Methods}

All chemicals used in this article were bought from Xi'an Kequan Laboratory Equipment Co.,Ltd (Xi'an, Shanxi province, China), except for the PMI-6T-TPA, which was bought from Suzhou Lvguang Chemical Co.,Ltd (Suzhou, Jiangsu province, China).

\subsection{Preparation of Hierarchical NiO/CMK-3 Nanocomposite and NiO Clusters}

Mesoporous CMK-3 was prepared by the procedure previously reported by Jun et al. [42]. In a typical synthesis of NiO/CMK-3 composite, $15 \mathrm{mg}$ of CMK-3 were dispersed into $40 \mathrm{~mL}$ of deionized water and sonicated for $5 \mathrm{~min}$. This was followed by the addition of $0.25 \mathrm{mmol}$ of $\mathrm{Ni}\left(\mathrm{NO}_{3}\right)_{2} \cdot 6 \mathrm{H}_{2} \mathrm{O}, 0.25 \mathrm{mmol}$ of hexamethylenetetramine (HMT), and $0.025 \mathrm{mmol}$ of citric acid trisodium salt dehydrate, in order to form a homogeneous green solution. This solution was then sonicated for a further $5 \mathrm{~min}$ and transferred into a $100 \mathrm{~mL}$ round-bottom flask. After magnetically stirring for $6 \mathrm{~h}$ at $90^{\circ} \mathrm{C}$ in an oil bath, the solution was then left to cool down to room temperature. A black precipitate was then obtained by centrifugation, which was washed thoroughly with ethanol and dried at ambient temperature overnight. The dried product was then further thermally treated at $600{ }^{\circ} \mathrm{C}$ under $\mathrm{N}_{2}$ atmosphere for $3 \mathrm{~h}$, at a heating rate of $1{ }^{\circ} \mathrm{C} \mathrm{min}^{-1}$.

$\mathrm{NiO}$ clusters were prepared via a similar procedure, without the addition of CMK-3.

\subsection{Materials Characterization}

The structure of the $\mathrm{NiO}$ nanomaterials were obtained using a Rigaku $\mathrm{X}$-ray diffractometer $(\mathrm{D} / \mathrm{max}-2500)$ with CuKa radiation $(\lambda=0.15418 \mathrm{~nm})$ at $40 \mathrm{~mA}$ and $40 \mathrm{kV}$. The data were collected in the $2 \theta$ range of $5-80^{\circ}$ with a scanning rate of $5^{\circ} \mathrm{min}^{-1}$ and a step size of $0.05^{\circ}$. The morphology was observed on a field-emission scanning electron microscope (FESEM; HITACHI, su-8010, Tokyo, Japan) and a transmission electron microscope (TEM; JEOL, JEM-2100, Tokyo, Japan). The elemental distribution was investigated on a scanning transmission electron microscope (STEM; JEOL, ARM200F, Japan), with an energy dispersive X-ray (EDX) spectrometer. X-ray photoelectron spectroscopy (XPS) analyses were tested with a PHI5300 analyzer (PerkinElmer, Waltham, MA, USA) with AlK radiation. Thermal Gravimetric Analysis (TGA, SDT Q600, New Castle, DE, USA) was carried out in an air atmosphere at a rate of $10{ }^{\circ} \mathrm{C} \mathrm{min}^{-1}$. $\mathrm{N}_{2}$ adsorption-desorption data were measured using a NOVA 2000e (Quantachrome, Boynton Beach, FL, USA) instrument, and the specific surface area was evaluated using the Brunauer-Emmett-Teller (BET) method.

\subsection{Preparation of the $\mathrm{NiO}$ and $\mathrm{NiO} / \mathrm{CMK}-3$ Films}

The photocathode semiconductor films were made by a two-step method on fluorine-doped tin oxide (FTO) conductive glass. NiO nanoparticles were first coated onto FTO using magnetron 
sputtering to form the compact layer. This was followed by applying a layer of either NiO/CMK-3 nanocomposite or $\mathrm{NiO}$ cluster, acting as the second light-scattering layer.

\subsection{Fabrication and Characterization of the p-DSSC Devices}

The prepared photocathodes were immersed in a PMI-6T-TPA dye solution (0.2 mM in DMF) for $12 \mathrm{~h}$. The photocathodes were then sandwiched together with platinized counter electrodes and sealed with Surlyn film. The electrolyte used was composed of $0.07 \mathrm{M}\left[\mathrm{Co}(\mathrm{en})_{3}\right]\left(\mathrm{BF}_{4}\right)_{3}, 0.3 \mathrm{M}\left[\mathrm{Co}(\mathrm{en})_{3}\right]\left(\mathrm{BF}_{4}\right)_{2}$, and $0.1 \mathrm{M}$ lithium bis (trifluoromethanesulfonylimide) (LiTFSI) in acetonitrile. The active electrode area employed was approximately $0.16 \mathrm{~cm}^{2}$. A Zahner CIMPS-2 electrochemical workstation (Kronach, Germany) together with a Trusttech CHF-XM-500W source (Beijing, China) under simulated Sun illumination (Global AM 1.5, $100 \mathrm{~mW} \mathrm{~cm}^{-2}$ ) were used to produce photocurrent-voltage (I-V) curves and electrochemical impedance spectra (EIS) $(100 \mathrm{kHz}$ to $0.1 \mathrm{~Hz}, 10 \mathrm{mV}$ perturbation). Intensity-modulated photovoltage spectroscopy (IMVS) and intensity-modulated photocurrent spectroscopy (IMPS) were carried out using a Zahner CIMPS-2 system. The lamp assembly was fitted with a blue light-emitting diode (LED) $(470 \mathrm{~nm}$ ) and driven by a PP210 (Zahner) frequency response analyzer, with a frequency range from $1000 \mathrm{~Hz}$ to $0.01 \mathrm{~Hz}$. The incident photon-to-electron conversion efficiency (IPCE) experiments were performed using a system consisting of a Xe lamp $(300 \mathrm{~W})$ with a monochromator (Oriel 74100, Newport Corp., Irvine, CA, USA).

\section{Conclusions}

In summary, a hierarchical $\mathrm{NiO} / \mathrm{CMK}-3$ nanocomposite was synthesized using CMK-3 as a templet and backbone to support and avoid the $\mathrm{NiO}$ nanoparticles aggregation. The hierarchical nanostructure possesses a large surface area that can absorb many more dye molecules and trap more light. A $p$-DSSC device fabricated using NiO/CMK-3 photocathodes showed photovoltaic conversion efficiency as high as $1.48 \%$. The device also showed superior hole transport kinetics, fast hole transport, long hole lifetime, prohibition of recombination, and hole collection efficiency. The CMK-3 with so many channels can act as a split-flow high-speed channel for fast hole transport through the external circuit. The novel hierarchical $\mathrm{NiO} / \mathrm{CMK}-3$ nanocomposite is expected to be potentially applied as a photocathode for $p$-DSSCs.

Supplementary Materials: The following are available online at http://www.mdpi.com/1420-3049/25/7/1638/s1, Figure S1: The structure of the PMI-6T-TPA sensitizer, Figure S2: Schematic illustration of the synthetic process of the Ni-Precursor/CMK-3, Figure S3: (a) XPS survey scan of NiO/CMK-3 composite; (b) C1s XPS spectrum of NiO/CMK-3 composite, Figure S4: Short-circuit IMPS response (a), (c) and IMVS response (b), (d) for NiO/CMK-3 and $\mathrm{NiO}$ cluster, respectively, Figure S5: Fitted EIS plot of p-DSSCs made of two nanomaterials and the insert is calculated parameters, Table S1: The fitting errors of corresponding EIS parameters.

Author Contributions: Conceptualization, A.M.A.; S.D. supervised the work; J.Q. performed the experiments and wrote the manuscript; Z.F. participated in the experiments; J.W. helped draft the manuscript; H.M. analyzed the data. All authors have read and agreed to the published version of the manuscript.

Funding: This research was funded by the Research Foundation of Hunan Education Committee of China (grant number 18C0033) and the Science and Technology Project of Changsha City (grant number kq1907133).

Conflicts of Interest: The authors declare no conflict of interest.

\section{References}

1. Yella, A.; Lee, H.-W.; Tsao, H.N.; Yi, C.; Chandiran, A.K.; Nazeeruddin, M.K.; Diau, E.W.-G.; Yeh, C.-Y.; Zakeeruddin, S.M.; Grätzel, M. Porphyrin-sensitized solar cells with cobalt (II/III)-based redox electrolyte exceed 12 percent efficiency. Science 2011, 334, 629-634. [CrossRef] [PubMed]

2. Tan, R.; Wei, Z.; Liang, J.; Lv, Z.; Chen, B.; Qu, J.; Yan, W.; Ma, J. Enhanced open-circuit photovoltage and charge collection realized in pearl-like $\mathrm{NiO} / \mathrm{CuO}$ composite nanowires based p-type dye sensitized solar cells. Mater. Res. Bull. 2019, 116, 131-136. [CrossRef]

3. Bakker, T.M.; Mathew, S.; Reek, J.N. Lindqvist polyoxometalates as electrolytes in p-type dye sensitized solar cells. Sustain. Energ. Fuels 2019, 3, 96-100. [CrossRef] 
4. Sen, A.; Groß, A. Does Involving Additional Linker Always Increase the Efficiency of an Organic Dye for p-Type Dye-Sensitized Solar Cells? ACS Appl. Energy Mater. 2019, 2, 6341-6347. [CrossRef]

5. Langmar, O.; Fazio, E.; Schol, P.; de la Torre, G.; Costa, R.D.; Torres, T.; Guldi, D.M. Controlling Interfacial Charge Transfer and Fill Factors in CuO-based Tandem Dye-Sensitized Solar Cells. Angew. Chem. Int. Ed. 2019, 58, 4056-4060. [CrossRef]

6. Nattestad, A.; Mozer, A.J.; Fischer, M.K.; Cheng, Y.-B.; Mishra, A.; Bäuerle, P.; Bach, U. Highly efficient photocathodes for dye-sensitized tandem solar cells. Nat. Mater. 2010, 9, 31-35. [CrossRef]

7. Odobel, F.; Le Pleux, L.; Pellegrin, Y.; Blart, E. New photovoltaic devices based on the sensitization of $p$-type semiconductors: Challenges and opportunities. Acc. Chem. Res. 2010, 43, 1063-1071. [CrossRef]

8. Gong, J.; Sumathy, K.; Qiao, Q.; Zhou, Z. Review on dye-sensitized solar cells (DSSCs): Advanced techniques and research trends. Renew. Sust. Energ. Rev. 2017, 68, 234-246. [CrossRef]

9. Wood, C.J.; Summers, G.H.; Clark, C.A.; Kaeffer, N.; Braeutigam, M.; Carbone, L.R.; d'Amario, L.; Fan, K.; Farré, Y.; Narbey, S. A comprehensive comparison of dye-sensitized $\mathrm{NiO}$ photocathodes for solar energy conversion. Phys. Chem. Chem. Phys. 2016, 18, 10727-10738. [CrossRef]

10. Brisse, R.; Faddoul, R.; Bourgeteau, T.; Tondelier, D.; Leroy, J.; Campidelli, S.; Berthelot, T.; Geffroy, B.; Jousselme, B. Inkjet printing NiO-based p-type dye-sensitized solar cells. ACS Appl. Mater. Inter. 2017, 9, 2369-2377. [CrossRef]

11. Bonomo, M.; Di Girolamo, D.; Piccinni, M.; Dowling, D.P.; Dini, D. Electrochemically Deposited NiO Films as a Blocking Layer in $p$-Type Dye-Sensitized Solar Cells with an Impressive $45 \%$ Fill Factor. Nanomaterials 2020, 10, 167. [CrossRef] [PubMed]

12. Bonomo, M.; Dini, D.; Decker, F. Electrochemical and photoelectrochemical properties of nickel oxide (NiO) with nanostructured morphology for photoconversion applications. Front. Chem. 2018, 6, 601. [CrossRef] [PubMed]

13. Awais, M.; Gibson, E.; Vos, J.G.; Dowling, D.P.; Hagfeldt, A.; Dini, D. Fabrication of Efficient NiO Photocathodes Prepared via RDS with Novel Routes of Substrate Processing for $p$-Type Dye-Sensitized Solar Cells. Chem Electro. Chem 2014, 1, 384-391. [CrossRef]

14. Liu, Q.; Wei, L.; Yuan, S.; Ren, X.; Zhao, Y.; Wang, Z.; Zhang, M.; Shi, L.; Li, D.; Li, A. Influence of interface properties on charge density, band edge shifts and kinetics of the photoelectrochemical process in p-type NiO photocathodes. RSC Adv. 2015, 5, 71778-71784. [CrossRef]

15. Odobel, F.; Pellegrin, Y. Recent advances in the sensitization of wide-band-gap nanostructured p-type semiconductors. Photovoltaic and photocatalytic applications. J. Phys. Chem. Lett. 2013, 4, 2551-2564. [CrossRef]

16. Muñoz-Garcia, A.B.; Caputo, L.; Schiavo, E.; Baiano, C.; Maddalena, P.; Pavone, M. Ab initio study of anchoring groups for $\mathrm{CuGaO}_{2}$ delafossite-based p-type dye sensitized solar cells. Front. Chem. 2019, 7, 158. [CrossRef]

17. Jiang, T.; Bujoli-Doeuff, M.; Farré, Y.; Pellegrin, Y.; Gautron, E.; Boujtita, M.; Cario, L.; Jobic, S.; Odobel, F. $\mathrm{CuO}$ nanomaterials for p-type dye-sensitized solar cells. RSC Adv. 2016, 6, 112765-112770. [CrossRef]

18. D'Amario, L.; Antila, L.J.; Pettersson Rimgard, B.; Boschloo, G.; Hammarström, L. Kinetic evidence of two pathways for charge recombination in NiO-based dye-sensitized solar cells. J. Phys. Chem. Lett. 2015, 6, 779-783. [CrossRef]

19. Yang, H.; Guai, G.H.; Guo, C.; Song, Q.; Jiang, S.P.; Wang, Y.; Zhang, W.; Li, C.M. NiO/graphene composite for enhanced charge separation and collection in p-type dye sensitized solar cell. J. Phys. Chem. C 2011, 115, 12209-12215. [CrossRef]

20. Powar, S.; Wu, Q.; Weidelener, M.; Nattestad, A.; Hu, Z.; Mishra, A.; Bäuerle, P.; Spiccia, L.; Cheng, Y.-B.; Bach, U. Improved photocurrents for p-type dye-sensitized solar cells using nano-structured nickel (II) oxide microballs. Energ. Environ. Sci. 2012, 5, 8896-8900. [CrossRef]

21. Fan, Z.; Liang, J.; Yu, W.; Ding, S.; Cheng, S.; Yang, G.; Wang, Y.; Xi, Y.; Xi, K.; Kumar, R.V. Ultrathin NiO nanosheets anchored on a highly ordered nanostructured carbon as an enhanced anode material for lithium ion batteries. Nano Energy 2015, 16, 152-162. [CrossRef]

22. Qu, J.; Yang, Y.; Shi, X.; Wang, W.; Ding, J.; Yuan, N.; Zhao, X.; Lai, C. Scalable synthesis of ultrasmall $\mathrm{SnO}_{2}$ nanocrystals in carbon conductive matrices: High loading and excellent electrochemical performance. J. Alloy. Compd. 2016, 686, 122-129. [CrossRef]

23. Wang, Y.; Rho, W.-Y.; Yang, H.-Y.; Mahmoudi, T.; Seo, S.; Lee, D.-H.; Hahn, Y.-B. Air-stable, hole-conductor-free high photocurrent perovskite solar cells with $\mathrm{CH}_{3} \mathrm{NH}_{3} \mathrm{PbI}_{3}-\mathrm{NiO}$ nanoparticles composite. Nano Energy 2016, 27, 535-544. [CrossRef] 
24. Park, J.H.; Seo, J.; Park, S.; Shin, S.S.; Kim, Y.C.; Jeon, N.J.; Shin, H.W.; Ahn, T.K.; Noh, J.H.; Yoon, S.C. Efficient $\mathrm{CH}_{3} \mathrm{NH}_{3} \mathrm{PbI}_{3}$ perovskite solar cells employing nanostructured $p$-type $\mathrm{NiO}$ electrode formed by a pulsed laser deposition. Adv. Mater. 2015, 27, 4013-4019. [CrossRef]

25. Seo, S.; Park, I.J.; Kim, M.; Lee, S.; Bae, C.; Jung, H.S.; Park, N.-G.; Kim, J.Y.; Shin, H. An ultra-thin, un-doped $\mathrm{NiO}$ hole transporting layer of highly efficient (16.4\%) organic-inorganic hybrid perovskite solar cells. Nanoscale 2016, 8, 11403-11412. [CrossRef]

26. Kwon, U.; Kim, B.-G.; Nguyen, D.C.; Park, J.-H.; Ha, N.Y.; Kim, S.-J.; Ko, S.H.; Lee, S.; Lee, D.; Park, H.J. Solution-processible crystalline $\mathrm{NiO}$ nanoparticles for high-performance planar perovskite photovoltaic cells. Sci. Rep. 2016, 6, 30759. [CrossRef]

27. Zhao, B.; Ke, X.-K.; Bao, J.-H.; Wang, C.-L.; Dong, L.; Chen, Y.-W.; Chen, H.-L. Synthesis of flower-like NiO and effects of morphology on its catalytic properties. J. Phys. Chem. C 2009, 113, 14440-14447. [CrossRef]

28. Langell, M.; Nassir, M. Stabilization of NiO (111) thin films by surface hydroxyls. J. Phys. Chem. 1995, 99, 4162-4169. [CrossRef]

29. Mrowec, S.; Grzesik, Z. Oxidation of nickel and transport properties of nickel oxide. J. Phys. Chem. Solids 2004, 65, 1651-1657. [CrossRef]

30. Uhlenbrock, S.; Scharfschwerdt, C.; Neumann, M.; Illing, G.; Freund, H.-J. The influence of defects on the Ni 2p and O 1s XPS of NiO. J. Phys.: Condens. Matter 1992, 4, 7973-7978. [CrossRef]

31. Abdelkader, A.; Fray, D. Controlled electrochemical doping of graphene-based 3D nanoarchitecture electrodes for supercapacitors and capacitive deionisation. Nanoscale 2017, 9, 14548-14557. [CrossRef] [PubMed]

32. Wang, Y.; Zheng, X.; Qu, Q.; Liu, G.; Battglia, V.S.; Zheng, H. A novel maleic acid/graphite composite anode for lithium ion batteries with high energy and power density. Carbon 2018, 132, 420-429. [CrossRef]

33. Xu, X.; Tan, H.; Xi, K.; Ding, S.; Yu, D.; Cheng, S.; Yang, G.; Peng, X.; Fakeeh, A.; Kumar, R.V. Bamboo-like amorphous carbon nanotubes clad in ultrathin nickel oxide nanosheets for lithium-ion battery electrodes with long cycle life. Carbon 2015, 84, 491-499. [CrossRef]

34. Li, L.; Gibson, E.A.; Qin, P.; Boschloo, G.; Gorlov, M.; Hagfeldt, A.; Sun, L. Double-layered NiO photocathodes for p-type DSSCs with record IPCE. Adv. Mater. 2010, 22, 1759-1762. [CrossRef]

35. Zannotti, M.; Wood, C.J.; Summers, G.H.; Stevens, L.A.; Hall, M.R.; Snape, C.E.; Giovanetti, R.; Gibson, E.A. Ni Mg mixed metal oxides for p-type dye-sensitized solar cells. ACS Appl. Mater. Inter. 2015, 7, 24556-24565. [CrossRef]

36. Zhang, X.L.; Zhang, Z.; Chen, D.; Bäuerle, P.; Bach, U.; Cheng, Y.-B. Sensitization of nickel oxide: Improved carrier lifetime and charge collection by tuning nanoscale crystallinity. Chem. Commun. 2012, 48, 885-9887. [CrossRef]

37. Wang, L.; Xing, H.; Gao, S.; Ji, X.; Shen, Z. Porous flower-like NiO@ graphene composites with superior microwave absorption properties. J. Phys. Chem. C 2017, 5, 2005-2014. [CrossRef]

38. Powar, S.; Daeneke, T.; Ma, M.T.; Fu, D.; Duffy, N.W.; Götz, G.; Weidelener, M.; Mishra, A.; Bäuerle, P.; Spiccia, L. Highly Efficient $p$-Type Dye-Sensitized Solar Cells based on Tris (1, 2-diaminoethane) Cobalt (II)/(III) Electrolytes. Angew. Chem. Int. Ed. 2013, 52, 602-605. [CrossRef]

39. Langmar, O.; Ganivet, C.R.; de la Torre, G.; Torres, T.; Costa, R.D.; Guldi, D.M. Optimizing CuO p-type dye-sensitized solar cells by using a comprehensive electrochemical impedance spectroscopic study. Nanoscale 2016, 8, 17963-17975. [CrossRef]

40. Qu, J.; Gao, X.; Li, G.; Jiang, Q.; Yan, T. Structure transformation and photoelectrochemical properties of TiO2 nanomaterials calcined from titanate nanotubes. J. Phys. Chem. C 2009, 113, 3359-3363. [CrossRef]

41. Chen, X.; Tang, Y.; Liu, W. Efficient dye-sensitized solar cells based on nanoflower-like ZnO photoelectrode. Molecules 2017, 22, 1284. [CrossRef] [PubMed]

42. Jun, S.; Joo, S.H.; Ryoo, R.; Kruk, M.; Jaroniec, M.; Liu, Z.; Ohsuna, T.; Terasaki, O. Synthesis of new, nanoporous carbon with hexagonally ordered mesostructure. J. Am. Chem. Soc. 2000, 122, 10712-10713. [CrossRef]

Sample Availability: Samples of the compounds are available from the authors. 